$\begin{array}{ll}\text { RefNum } & \text { JIASSCIENCE-36844 } \\ \text { Manuscript Category } & \text { Physical Education and Sports Teaching } \\ \text { Manuscript Type } & \text { Original Research } \\ \text { Received } & 18.01 .2019 \\ \text { Accepted } & 08.04 .2019 \\ \text { Corresponding Author } & \text { Boban Simic [bozana.cvijic@gmail.com]/ https://orcid.org/0000-0003-2354-1136 }\end{array}$

\title{
ANALYSIS AND DIAGNOSIS OF WEIGHT AND HEIGHT OF 3rd AND 4th GRADE PUPILS OF SECONDARY SCHOOL
}

\author{
Boban Simic ${ }^{1}$ \\ ${ }^{1}$ Department of master degrees, University of East Sarajevo, Faculty of physical education and Sport, Bosnia and \\ Herzegovina
}

\begin{abstract}
The sample of respondents for this research consisted of 44 respondents aged 16 to 19 from the territory of the Municipality of Ugljevik, or pupils of the "Mihailo Petrović Alas" secondary school. The aim of this paper was to analyse the body weight and height of pupils of the third and fourth grade of secondary school and determine the similarities and differences in the body mass of pupils of different ages. The gender sample of the respondents was unbalanced, hence the obtained indicators, i.e. the values were significantly higher for the pupils of the 3rd grade dominated by boys. For the purpose of measuring the weight and height of pupils, two anthropometric devices were used: scale and anthropometer. Differences between height, weight and body mass index of 3rd and 4th grade pupils of secondary school were determined by the T-test. The results showed that statistically there is a significant difference between the weight, height, and hence the body mass index of the respondents, all due to the unrepresentative sample dominated by boys in one group of the respondents.
\end{abstract}

Keywords: Weight, Height, Body Mass Index, Anthropometric Measurements.

\section{INTRODUCTION}

Every lifetime has its own needs for physical activity through sports or recreation. There is plenty of evidence that physical activity can prevent certain diseases or reduce their intensity, making it one of the most important factors in improving the health of a population (Gojković \& Trifković-Gojković, 2013). Regular physical activity of children and young adults is important for their growth and development, health and disease protection. When children start school, their lifestyle changes and their physical activity is significantly reduced. Physical inactivity can very early on be a significant factor of obesity and chronic diseases in school children. The physical development of every human being is a natural process and takes place according to natural laws, and it is under the strong influence of the inheritance (genetic factor) and the environment (social factor), and it is said with good reason that it is a kind of blend of the common action of genetics and the conditions of the social environment (Stević, 2011). Every person has a natural need for movement, and through physical education, it becomes a planned and deliberate activity, which is not only a means of improving functional and motor skills, but also a precondition for the development of other components of personality. Reduced motor activity has the greatest effect 
on the school population, which is also the most sensitive since it is in the development period. This population, through regular physical education, achieves $10-20 \%$ of natural needs for movement. However, the question arises: what about the other $80-90 \%$ of the need for movement, whether today's young adults meet this need and how much it affects the growth and the development curve.

Research conducted by Schafer et al. (1998) determined increased body mass among healthy children in Germany. The research involved 2554 children of both sexes and it was found that the values of the body mass index were continuously increasing during the growing up and the indicators were increasing as the measured children got older. According to research published by the Institute of Public Health of Serbia "Dr Milan Jovanović-Batut, more than half of the adult population of Serbia $(54 \%)$ has a problem of over-nutrition, with obesity most often escalating during the period of development in high school age (Vlajković et al., 2010). Murer et al., in (2016) a survey was conducted in children aged 12 to 18 in Switzerland to 2724 participants. Body height and body weight of the pupils were measured to calculate the body mass index. The results showed that $36.9 \%$ of subjects were overweight and obese. In Bosnia and Herzegovina Salihefendić, et al. (2016) conducted a research in (2016) on a sample of 1200 pupils. Anthropometric measurements were conducted and it was found that $12 \%$ of pupils had an excessive body mass, and 5\% of children were obese. In the developed countries, in many researches, excessive nutrition and obesity have been identified, and Muthuri in (2014) attempted to find data on the state of the body index in less developed countries and explored the area of sub-Saharan Africa where respondents were children and adolescents from 5 to 17 years of age. Both in developed countries, and in these countries, there is a trend of increasing ratio of overweight and obese children, as well as a large number of malnourished children. Therefore, in these countries, the degree of abnormal occurrence is increased, and the percentage of normally nourished children is reduced. Body measurement values were higher in girls, children in urban areas and children with better socioeconomic status.

\section{METHODS}

Sample of respondents

The study was conducted on a sample of 44 examinees, aged 16 to 19 years. For the needs of the research, a sample of pupils from the Mihailo Petrović Alas school in Ugljevik was taken, of which 29 were male and 15 female who had a physical education class on 7 December. Measurement, ie testing, was carried out in the gym in Ugljevik.

Sample variables

The following variables have been selected for the analysis and diagnosis of weight and height of 3rd and 4th grade pupils: Body height $(\mathrm{cm})$, Body mass (kg), Body mass index - BMI.

\section{Description research}

The research was conducted on 3rd and 4th grade pupils of the "Mihailo Petrovic Alas" secondary school in Ugljevik. Measurements of the weight and height of the pupils were carried out in order to obtain the necessary results, i.e. pupils of the third grade of car mechanics, and of the fourth grade of gymnasium who had a physical education class on that particular day. Full study included a total of 44 examinees, of which there were 29 boys and 15 girls, of which 2 pupils born in 1998, 22 pupils in 1999, 15 pupils in 2000 and 6 in 2001. The measurements were made at the beginning of the class, on 7 December 2017 by measuring their body and height before the warm-up, and in the manner described below. After the research, it was found that slightly more than $70 \%$ of pupils had a normal body weight and height ratio, i.e. the corresponding body mass index, while slightly less than $30 \%$ belong to the category of abnormal, i.e. overweight, obese and malnutritioned.

\section{Sample of measuring instruments}

For the purpose of measuring the weight and height of the pupils, two anthropometric devices were used, scale and anthropometer. As the subject school does not have a decimal scale with a moving weight and accuracy of $0.1 \mathrm{~kg}$ when operating correctly (Parasmani \& Roland, 2001), my own spring-balance scale was used for the research with accuracy of up to $0.5 \mathrm{~kg}$ and its accuracy was reduced due to the spring susceptible to the elements. Anthropometer was used for measuring the height, a two hundred and twenty-centimetre long angular metal rod with a 
sliding part moving along its entire length (Frank \& Tanner, 2013). The accuracy of this instrument is $0.1 \mathrm{~cm}$, and the value is expressed through a horizontal crossbar that lies at the top of an anthropometric measuring point. Therefore, the required values were read in relation to the red line located in the middle of a square hole.

The weight of the body is measured by a scale placed on the horizontal flooring (Pržulj \& Cicović, 2012). The pupils' body weight was measured with them wearing their shorts and t-shirts, barefoot, standing in the centre of the scale placed on a horizontal surface, standing steadily and upright. After the weighing, with an accuracy of $0.5 \mathrm{~kg}$, the required information was entered by rounding the body mass to a lower value.

After measuring the weight of all pupils in one of the classes, the height was measured, in a way that pupils stood barefoot, in sports equipment - shorts and t-shirts, in an upright position on a firm horizontal surface. The head of the pupil was in upright position, with a view directed toward the Frankfort horizontal. The back of the pupil during the measurement was held straight as far as possible, hands lowered down the body, and the feet held together. As an examiner, I stood on the left side of the pupil and checked whether the anthropometer was positioned correctly, or directly along the back of the body and vertically. After checking, a metal slider is slowly lowered

so that the horizontal crossbar comes to the head the top of the head, after which the result was read with an accuracy of $0.1 \mathrm{~cm}$.

After establishing the main indicators, height and weight of the body, the body mass index was calculated, being a statistical indicator of the nutrition of an individual. I calculated the body mass index of each individual pupil in such a way that I divided the body mass, that is, the mass of a person expressed in kilograms with the height of a person expressed in meters. This index is a simple numerical measure that shows how fat or thin someone is. People who have BMI below 18.5 are undernourished, while those over 25 are over nourished. BMI below 17.5 is a sign that a person may suffer from anorexia, and a value over 30 is an obesity indicator.

\section{Data processing methods}

All data was processed with the SPPS statistical package. Descriptive statistical methods were applied to calculate the arithmetic mean, minimum and maximum result, and standard deviation. For the determination of the differences between the mean values at the significance level of $95 \%(p<0.05)$, the "T test" for the samples was used.

\section{RESULTS}

Table 1. Basic descriptive data for 3rd and 4th grade pupils (height)

\begin{tabular}{lcccccc}
\hline & $\mathrm{N}$ & Minimal & Maximum & $\begin{array}{c}\text { Arithmetic } \\
\text { mean }\end{array}$ & $\begin{array}{c}\text { Standard } \\
\text { deviation }\end{array}$ & $\begin{array}{c}\text { Standard error } \\
\text { (Standard error mean) }\end{array}$ \\
\hline III Class & 22 & 167 & 192 & 179.55 & 7.54 & 1.61 \\
\hline IV Class & 22 & 156 & 193 & 169.18 & 10.90 & 2.32
\end{tabular}

The average body height of 3rd pupils is $179.55 \pm 7.54 \mathrm{~cm}$, while the average height of the pupils in the 4th grade is $169.18 \pm 10.90 \mathrm{~cm}$.

Table 2. Basic descriptive data for 3rd and 4th grade pupils (weight)

\begin{tabular}{ccccccc} 
& N & Minimal & Maximum & $\begin{array}{c}\text { Arithmetic } \\
\text { mean }\end{array}$ & $\begin{array}{c}\text { Standard } \\
\text { deviation }\end{array}$ & $\begin{array}{c}\text { Standard error } \\
\text { (Standard error mean) }\end{array}$ \\
\hline III Class & 22 & 60 & 95 & 77.14 & 9.21 & 1.96 \\
\hline IV Class & 22 & 47 & 86 & 62.77 & 12 & 2.56
\end{tabular}

The body average weight of 3rd pupils is $77.14 \pm 9.21 \mathrm{~kg}$, while pupils of 4 th grade have an average weight of $62.77 \pm 12 \mathrm{~kg}$. 
Table 3. Basic descriptive data for 3rd and 4th grade pupils (BMI)

\begin{tabular}{lcccccc} 
& N & Minimal & Maximum & $\begin{array}{c}\text { Arithmetic } \\
\text { mean }\end{array}$ & $\begin{array}{c}\text { Standard } \\
\text { deviation }\end{array}$ & $\begin{array}{c}\text { Standard error } \\
\text { (Standard error mean) }\end{array}$ \\
\hline III Class & 22 & 18.30 & 28.74 & 23.8518 & 2.8448 & 0.6065 \\
\hline IV Class & 22 & 17.65 & 31.22 & 21.8114 & 3.4036 & 0.7256
\end{tabular}

The index of body mass for the pupils of 3rd grade take out 23.8518 , while in the 4th grade pupils it is 21.8114 .

Table 4. Determination of difference in height, weight and body index between pupils of 3rd and 4th grade at a level of significance of $95 \%(r<0.05)$

\begin{tabular}{cccccc} 
& $\begin{array}{c}\text { Artificial } \\
\text { midpoint of 3rd } \\
\text { grade pupils }\end{array}$ & $\begin{array}{c}\text { Artificial midpoint } \\
\text { of pupils of 4th } \\
\text { grade }\end{array}$ & $\mathrm{t}$ - value & Critical value - p & $\begin{array}{c}\text { Standard Error of } \\
\text { Difference }\end{array}$ \\
\hline Physical height & 179.55 & 169.18 & 3.6687 & 0.0007 & 2.825 \\
\hline Body weight & 77.14 & 62.77 & 4.4532 & 0.0001 & 3.225 \\
\hline $\begin{array}{c}\text { Body Mass } \\
\text { Index }\end{array}$ & 23.8518 & 21.8114 & 2.1575 & 0.0367 & 0.946
\end{tabular}

From Table 4 it can be seen that there are significant differences between the weight, height and body mass index of 3rd and 4th grade pupils because the critical value indicator is smaller than 0.05 in all cases.

\section{DISCUSSION}

The average body height of 3rd pupils is $179.55 \pm 7.54 \mathrm{~cm}$, while the average height of the pupils in the 4th grade is $169.18 \pm 10.90 \mathrm{~cm}$. So, the younger grade pupils are taller than the elder one. These results are not ordinary considering other observation of scientist and logical conclusions. Is it means that with the growth the pupils become smaller? All research about the height of young people - grade pupils of secondary school have opposite results than we get in this research in a way that the body height of 3rd pupils is smaller than the height of the pupils in the 4th grade. After a similar research project, Kovačević, et. al., (2018) gets the results that the average body height of 3rd pupils is $169 \pm 6.33 \mathrm{~cm}$ until the average body height of the pupils in the 4th grade is $183 \pm 5.99 \mathrm{~cm}$. But in the same type of research, the differences are not so big, and the average body height is largely equated. However, differences in the average height are not so various if the structure of examines is uniform (Kutle \& Anić, 2019). The results obtained are diametric in relation to the age of the respondents, however, this is because boys dominated in the third-grade sample, their bodies being naturally bigger, and they are taller than girls. We can conclude that with the age and growth grade pupils do not have smaller body height, on the contrary, they are in ages when growing. These results are a consequence of an unusual type of two opposite types of classes considering gender, age, and occupation.

The result obtained in terms of the body weight of 3 rd pupils is similar to the result obtained in terms of height, since they have an average weight of $77.14 \pm 9.21 \mathrm{~kg}$, while pupils of 4 th grade have an average weight of $62.77 \pm 12 \mathrm{~kg}$. This obtained indicator is the result of the different structure of the respondents, because boys are mostly being educated to be car mechanics and have larger muscles. Our observations confirm other researches because in this period the grade pupils suffer from major pubertal changes that caused more weight that is usually. The average weight is not drastically different considering the structure of examinees. The founded difference in weight is a consequence of other factors such is irregular nutrition, sports or on other side absence of physical activity. Similar was founded by others when examined the average weight of grade pupils and get that the pupils of $3 \mathrm{rd}$ grade have $74,31 \mathrm{~kg} \pm 17$, otherwise pupils of 4 th grade

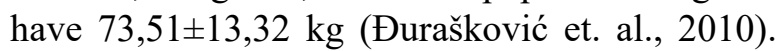


During this, it is clear that the founded results are confirmed with another one, and the differences can be seen only in the slightly lower scope of differences average, although the deviations are fairly uniform. Therefore, according to general statistic and research done by BATUT, more than half of the adult population on Balkan has a problem of over nutrition, with obesity most often escalating during the period od development in high school age (Vlajković et. al., 2010). Our examinees are not included in this category of fat pupils, because the most over result of weight is 95 $\mathrm{kg}$ which number is not too highest for eventually minimal height of $167 \mathrm{~cm}$. So, the differences in the average body weight of the pupils in the 3rd grade and of the pupils in the 4th grade, and the highest body weight of younger pupils is not exception considering the domination of boys.

When these two variables - height and weight are placed in mutual relation, an index of body mass is obtained which is an arithmetic mean in the pupils of 3 rd grade 23.8518, while in the 4th grade pupils it is 21.8114. By observing the given results, we conclude that this is a group of normally nourished children. Since the deviation from the mean result in 3rd grade pupils is 2.8448 , and given the average BMI, the result may indicate overly nourished children in the sample, while the deviation among the pupils of the 4th grade shows a greater chance of having malnourished children, and which is also visible from the minimum BMI value of the sample in question. Therefore, it is evident that pupils of the third grade tend to be overly nourished, while fourth graders are closer to malnutrition, and they represent two diameters of one scale. Other researchers, like Dačević (2013) did not found some differences in results, and during him, all diversity that exist in BMI is in permit scale. The results is rating from 17.65 to 31.22 , and standard deviation do not crossing the number of 3.5 which is more than good result. So this means that we confirmed the theory that grade pupil in Balkan are not so far from pretil or underfed grade in isolated cases, otherwise both examined groups confirmed that the normal BMI prevailed.

From all this result it can be seen that there are significant differences between the weight, height and body mass index of $3 \mathrm{rd}$ and 4 th grade pupils because the critical value indicator is smaller than 0.05 in all cases. This result is consequence of all factors that determined research that was completed. In basis, we have two samples that comparate in critical points, and results are different than expected. We get the inversion of expected results during the examples. We believe that if we done the research on more equible examples that results would be more related, but the purpose of research is not to examined the subject with already excepted parameters.

\section{CONCLUSION}

The aim of this research was to establish the normality, ie the abnormality of the weight and height of pupils in secondary school age. Although the World Health Organization and leading experts point to obesity and improper development of children and young adults, especially in the period of secondary school age, this research has not identified a worrying number of obese or underweight pupils. The reason for moderate results and slight deviations from the normal body index can be attributed to the great physical activity of pupils due to the various sports offered in the school where the examination was conducted. A greater number of overweight people appear in younger generations, or individuals whose physical development is not yet complete, however excessive nutrition in this category of pupils can be corrected by increased physical activity (due to the border line index between normal and excessive nourishment) and cannot be considered alarming since by examining older generations it was found that deviations from normal body weight are corrected in a year or two (the age difference between subjects) of physical development and physical activity.

After the research was carried out, there were significant differences between the height, weight and index of the body weight of pupils of the third and fourth grade. On the basis of the collected data on body weight, height and body mass index, it can be said that in order to produce more relevant results, the research should be carried out on larger and more representative samples, that is, above all, more diverse structures in terms of occupation, sex, social factors and other factors that may be relevant for physical development.

\section{REFERENCES}

Gojkovic, D. \& Trifković-Gojković V. (2013) Corrective-gymnastic prevention of postural disorders of the spinal column, p.3, 1st Edition, East Sarajevo: 
Faculty of physical education and sport Pale, DIS-Copy Company.

Dačević, R. (2013) Comparative analysis of the postgraduate status and anthropomotoric of young students and pupils of the same ages, Podgorica: University of Montenegro, Faculty of sport and physical education. p. 37.

Đurašković, R., Sinanović, J., Bojić, I. \& Ranđelović, J. (2010) Selection basis for sport in the municipality of Tutin, Codex of articles Faculty of physical education Niš, p.587.

Frank, F. \& JM Tanner (2017) Human Growth: Postnatal Growth, p. 48, 2nd Edition, New York: Springer Science+Business Media New York. Available from URL: https://link.springer.com/content/pdf/ bfm\%3A978-1-4899-0522-2\%2F1.pdf Accessed 23rd December.

Kovačević, A, Kvesić, M. \& Kuna, D. (2018) Antropological characeristics grade pupils considering the gender, 6th Fiep European Congress. Available from URL: https://www.hrks.hr Accessed 18th January.

Kutle, I. \& Anić N. (2019) Differences in the body weight index between students of the the high school in urban and in rural environment, Summer school of kinesiologists of Croatia. Available from URL: https:// www.hrks.hr Accessed 27th March.

Murer, S., Saarsal, S., Zimmermann, J., Herter-Aeberli, I. (2016) Risk factors for overweight and obesity in Swiss school children: results from a representative national survey, European Journal of Nutrition, p. 625.

Muthuri, S. (2017) Evidence of an overweight / obesity transition among school-aged children and youth in Sub-Saharan Africa, s. 12 screens/inclusive page. Available from URL: www.ncbi.nlm.nih.gov Accessed 28th December.

Parasmani, D. \& Roland, H. (2001) Perspectives in human growth, development and maturation, p. 49, 27th Edition, Dordrecht: Kluwer Academic Publishers.

Pržulj, D. \& Cicović, B. (2012) Diagnostics of anthropological characteristics and training of athletes, p. 53, 1st Edition, East Sarajevo: University of East Sarajevo, Grafosemberija Company.

Salihefendić, N., Zildžić, M. \& Jašić, M. (2017) Promoting healthy lifestyles school children: role of the local community (Review of the results of the project "Let's go back children in sports"). Food in Health and Diseases: a scientific-professional journal for nutrition and dietetics, p. 8- 9 screens/inclusive pages. Available from URL: https://hrcak.srce.hr/173862 Accessed 25th December.
Schaefer, F., Georgi, M., Wühl, E. \& Schärer, G. (2018) Body mass index and percentage fat mass in healthy German schoolchildren and adolescents. Inter J Obes, s. 461 screens/inclusive page. Available from URL: https://www.nature.com/articles/0800608. pdf?origin=ppub Accessed 2nd January.

Stevic, D. (2011) Theoretical foundations of physical culture and sport , p. 15, 1st Edition, Bijeljina: Teacher Education Faculty, Grafosemberija Company.

Vlajković, V., Macanović, G., Arsić, J., Jocić, I., Milovanović, D. \& Arsic, D. (2010) Obesity among school children as a risk factor for health, p. 10, PONS Medical Journal. 